\title{
COM \\ Credibility aspects of research-based gaming in science communication - the case of The Maladaptation Game
}

\section{Therese Asplund}

\begin{abstract}
While previous studies have found games and gaming to be a new and innovative communication strategy to inform the public and citizens about scientific research and engage them with it, this article addresses the under-researched question of credibility aspects in research-based gaming. The study analyses agricultural stakeholders' discussions on the credibility of scientific descriptions in The Maladaptation Game - a game based on research on climate change maladaptation in Nordic agriculture. The analysis of focus group transcripts and frame credibility finds that players attribute credibility to 1) the perceived correspondence between game-articulated information on climate change, suggested adaptation actions and their potential maladaptive outcome, 2) the perceived "fit" between these elements and players' experiences, and 3) the information sources underpinning the game. Lastly, the article discusses the role of research-based games in science communication and advocates the need for careful balance between models of conceptual and scientific thinking in game design and everyday experiences among players.
\end{abstract}

Keywords

DOI

Introduction literature insights into the role of games and gaming for science communication
Environmental communication; Public perception of science and technology

https://doi.org/10.22323/2.19010201

Submitted: 10th June 2019

Accepted: 2nd December 2019

Published: 13th January 2020
The use of digital and online games has increased rapidly in recent years, suggesting that gaming is now part of everyday life for many. With the global games audience estimated at 2.3 billion people, and the global market expected to grow rapidly ${ }^{1}$ [Wijman, 2018], the potential of gaming for advancing science communication is gaining increased societal interest. For instance, some studies

\footnotetext{
${ }^{1}$ In 2017 , Newzoo expected the global market to grow at an annual rate of $+6.2 \%$ towards 2020 . Latin America is calculated to have a $20.1 \%$ year-on-year increase, while Asia-Pacific territories have an estimated year-on-year increase of $9.2 \%$. North America has an estimated year-on-year growth rate of $4.0 \%$, and Western Europe a growth rate of $4.4 \%$. Eastern Europe, meanwhile, has an estimated year-on-year growth rate of 7.3\%. [McDonald, 2017].
} 
have confirmed that online games and gaming offer great potential as a novel and innovative communication strategy to inform the public and citizens about scientific research and engage them with it. In a study of online climate change games, Ouariachi, Olvera-Lobo and Gutiérrez-Pérez [2017] argue that games may offer an alternative to conventional media for delivering information. The relationships between game narrative and design and the communication of explicit meanings and implicit values, they argue, make games "innovative communication tools" [Ouariachi, Olvera-Lobo and Gutiérrez-Pérez, 2017, p. 36]. Similarly, Fitts Willoughby and Smith [2016, p. 537] argue that "new media [e.g. games and gaming] strategies have the potential to allow practitioners to tailor messages to varying audiences across the globe". Equally, Dudo et al. [2014] claim that it is important for science communication scholars to consider the potential of modern digital games to engage players with science in "novel, memorable ways" (p. 221) that contribute to their understanding, perceptions, and even behaviors".

As actors involved in online science engagement turn to games to bring science to a potentially large audience, scholars have not only identified the promise of games and gaming for science communication but have also uncovered challenges. The challenges of gaming mainly concern the integration of science within a gaming environment [Curtis, 2014], and a successful communication relation between science and society [Burnet, 2010]. Such a communication relation, Burnet claims, requires circumstances in which the public meets scientists face to face. According to Burnet [2010], a fundamental role is played not only by the mediator, but also by the scientist. He argues that the presence of an academic researcher is crucial if the aim is to create contact between the scientific world and civil society. In a similar fashion, Curtis [2014] finds that research-based games may serve as a stimulus for increased dialogue or contact with the scientific community, as games can enable players to discuss any issues that the game raises, either with each other or with scientists. Hence, the interpretative horizons of game players are central to the understanding of how science and research can be better communicated through games.

In sum, while studies pinpoint the promise of online and research-based games [Burnet, 2010; Curtis, 2014; Dudo et al., 2014; Fitts Willoughby and Smith, 2016; Ouariachi, Olvera-Lobo and Gutiérrez-Pérez, 2017], limited empirical research has been performed into credibility aspects of research-based games and gaming. Yet it is widely recognized that the appeal of any information used in communication is influenced by the extent to which it resonates with the worldviews of its audiences [Snow and Benford, 1988], and therefore gaming in science communication is expected to raise concerns about the communicative aspects of credibility and legitimacy.

In line with environmental and science communication studies on audience segmentation [for an overview, see Wibeck, 2014], this study offers an audience-specific departure point to explore credibility aspects of research-based gaming in science communication. Agriculture is a sector that has been identified as relevant to societal responses to climate change. Although information is generally regarded as a factor determining the capacity to adapt to and mitigate climate change [IPCC, 2007], studies have found that farmers differ from the general public in terms of how they make sense of climate change [Moser, 2010] and climate change information [Hansen, Marx and Weber, 2004], thus justifying a particular focus on how farmers make sense of climate change information. 
Furthermore, as the use of digital tools and interactive technologies for farming systems has increased rapidly in recent years, this motivates studies concerning trust, transparency and dialogue [Jakku et al., 2019; Lazzaro et al., 2018]. By analysing players' discussions while playing The Maladaptation Game, this paper aims to explore how players perceive the credibility of game-mediated research on climate change maladaptation. Specifically, the article addresses the following theoretically informed research questions:

- In what ways are the players attributing credibility to the correspondence between game-articulated information on climate change, suggested adaptation actions and their potential maladaptive outcome?

- In what ways are the players attributing credibility to the "fit" between game-mediated information and their personal experiences?

- In what ways are the players attributing credibility to the research constructing the game?

Theoretical and analytical approaches to credibility
Whether a message is successful or not can be said to depend on its resonance with the intended recipient or audience [Benford and Snow, 2000]. The concept of resonance describes the mobilizing potency of an idea or storyline, and explains why some framings seem to be effective or to resonate while others do not [Benford and Snow, 2000; Snow and Benford, 1988]. Benford and Snow [2000] argue that the credibility of any framing is a function of three factors: frame consistency, empirical credibility, and the credibility of frame articulators. Frame consistency refers to the correspondence between articulated beliefs, claims, and actions. Empirical credibility refers to the perceived "fit" between frames and events in the world, and concerns questions such as "Can the claims be empirically verified?" [Benford and Snow, 2000, p. 620]. The empirical credibility of a framing thus concerns the "evidence" substantiating claims. The third factor informing judgements of frame credibility concerns the perceived credibility of the frame articulators. In conclusion, it has been theoretically suggested [Snow and Benford, 1988], with empirical support [e.g. Wolf and Moser, 2011], that information is always and inevitably filtered through pre-existing worldviews. Hypothetically, if the information in The Maladaptation Game is consistent and associated evidence claims and their articulators are deemed credible from the audience's point of view, the ideas or storylines of the game are likely to have a strong appeal. As Hahn, Harris and Corner [2016] concluded, set against these (hypothetical) considerations, it seems striking how limited research into these issues has been in the climate context more generally [2016].

In studies of human sense-making, two divergent approaches can be applied: the cognitive and the interactional. While the cognitive approach views people as individual information processers who use memory structures that help to organize and interpret incoming information, the interactional approach portrays people as conversationalists who interact while co-constructing the meanings of their worlds [for an overview, see Dewulf et al., 2009]. In the cognitive approach, ideas and storylines are considered relatively static entities, and consequently this approach focuses on the transmission of messages, or how people experience, interpret, or represent issues [cf. Fiske, 1990]. To explore how players perceive the credibility of game-mediated research on climate change maladaptation, this article 
is inspired by the interactional approach. Treating information and ideas as interactional co-constructions implies a shift in focus to ongoing processes of interaction [Dewulf et al., 2009]. In this approach, meaning is seen as located between people in interaction and thus refers to communication as the production and exchange of meaning [cf. Fiske, 1990].

More recently, a small number of empirical studies have noted the relevance of the credibility of sources, content, and processes for successful climate change communication. For example, Attari, Krantz and Weber [2016] found that climate researchers' credibility stands in relation to their carbon footprints and may suffer when they advocate specific policies [Kotcher et al., 2017]. Furthermore, Jarreau, Altinay and Reynolds [2017] highlighted the importance of selecting experts who have experience, and credibility, within a given community and who can tailor messages to the audience to which they are speaking. Studies have demonstrated that some audiences rely primarily on formal communicators, such as scientists and politicians, for information about climate change solutions while others rely more on various informal communicators [Sleeth-Keppler, Perkowitz and Speiser, 2017], such as Pope Francis [Li et al., 2016]. Similarly, various actors in certain countries - such as Tanzania [Amars et al., 2017], Uganda [Twongyirwe et al., 2015], and Eastern Africa [Egeru, 2016] — ascribe low credibility to government actors while perceiving civil society organizations and community meetings to be more accessible, reliable, and dependable information sources. Studies concerned with empirical credibility confirm the relevance of differing requirements for evidence, in that some actors needed scientific validation while others sought experiential knowledge [Asplund, 2018; Ingram, Mills et al., 2016; White et al., 2015].

\section{Credibility and climate maladaptation}

As previously noted, The Maladaptation Game mediates research on climate maladaptation in the agricultural sector. While Nordic agriculture may benefit from climate change, it is also extremely vulnerable to its impacts [Olesen and Bindi, 2002; Olesen, Børgesen et al., 2012]. Changes in weather extremes are likely to affect agriculture, and over the coming century Nordic agriculture might face changes in temperature and precipitation as well as increasing variability, including heatwaves and heavy precipitation. Climate maladaptation is a concept that addresses the potential negative aspects of climate adaptation. As such, the maladaptation concept refers to increased vulnerability within targeted or non-targeted sectors or social groups [Barnett and O'Neill, 2010; Juhola, Glaas et al., 2016]. While the Intergovernmental Panel on Climate Change (IPCC) recognizes the need for adaptation action for agriculture, potential maladaptation in agriculture has not been substantially investigated [IPCC, 2014], and specifically not for the Nordic countries. In that context, The Maladaptation Game was developed as a research method to identify thresholds for maladaptation in Nordic agriculture (http:/ / maladaptationgame.info/). As argued by Benford and Snow [2000], however, audiences do not perceive all information to be equally acceptable but judge the credibility of claims and arguments. This study adopts an interactional approach to the study of credibility, and as such argues that frame credibility occurs in the dialogues and interactions between ideas as presented in the game and players' responses to its credibility [cf. Marková et al., 2007]. Consequently, 
this study analyses not only the players' perceptions of the credibility of The Maladaptation Game but also their joint elaborations on these perceptions.

\section{Materials and methods}

\section{The Maladaptation Game - a game based on climate change maladaptation research}

The Maladaptation game is based on scientific research on the potential negative impacts of climate adaptation measures. To identify maladaptive outcomes, the interdisciplinary project team 1 ) performed a literature review and presented a typology of maladaptation [Juhola, Glaas et al., 2016], 2) conducted interviews with farmers and extension officers in Sweden and Finland [Juhola, Klein et al., 2017], and 3) synthesized literature and interviews with farmers, agricultural officials, and experts in Sweden and Finland [Neset et al., 2019].

The design of the game presents four climate change-related challenges for Nordic crop production: drought, a longer growing season, changing precipitation patterns, and increased risk of pests and weeds (see Figure 1). Each challenge includes a number of different adaptation measures, and each adaptation option generates several (potentially negative) effects. For instance, with increased or changing patterns of precipitation come various options to adapt, e.g. investing in improved drainage systems or drying equipment, or farm management strategies such as practising no tillage, applying structural liming or ploughing the sub-soil. With each of these adaptation measures comes one or more potentially negative consequences: increased nutrient leakage, increased water flows, increased costs, increased energy costs and potential $\mathrm{CO}_{2}$ emissions, increased need for pesticides, decreased drainage capacity of the soil, increased soil compaction, or increased risk of erosion and nutrient leakage. The players choose how to adapt to each of the four climate challenges and, based on their preferences, accept its potential maladaptive outcome. In addition, all of the adaptation measures cost an amount of money, which is represented by the illustration of a coin, and generate an M-score, a maladaptive outcome. The player with most coins left while producing the lowest M-score wins the game.

The Maladaptation Game was designed to support dialogue to better understand how agricultural actors make decisions regarding adaptation as they simultaneously have to consider potential maladaptive outcomes (http:/ / maladaptationgame.info/). The games was found to both support and hinder players' sense-making processes around climate change maladaptation in various ways [Asplund et al., 2019]. In a study design similar to this one, focus group participants' perspectives on the benefits and challenges of playing The Maladaptation Game were analysed. The results show that the game stimulated joint reflection from participating players because it requires the active processing of information and perspectives as players choose, think, and jointly discuss climate adaptation and maladaptation, taking the game as a starting point. At the same time, participants voiced concerns about the lack of a context-relevant game narrative, and repeatedly expressed that they experienced a lack of context-relevant choices. While the previous study focused on the benefits and challenges of The Maladaptation Game, this study offers a theoretically informed analysis of the appeal of the game-mediated information on climate maladaptation. By analysing players' discussions while playing The Maladaptation Game, this paper asks how players 


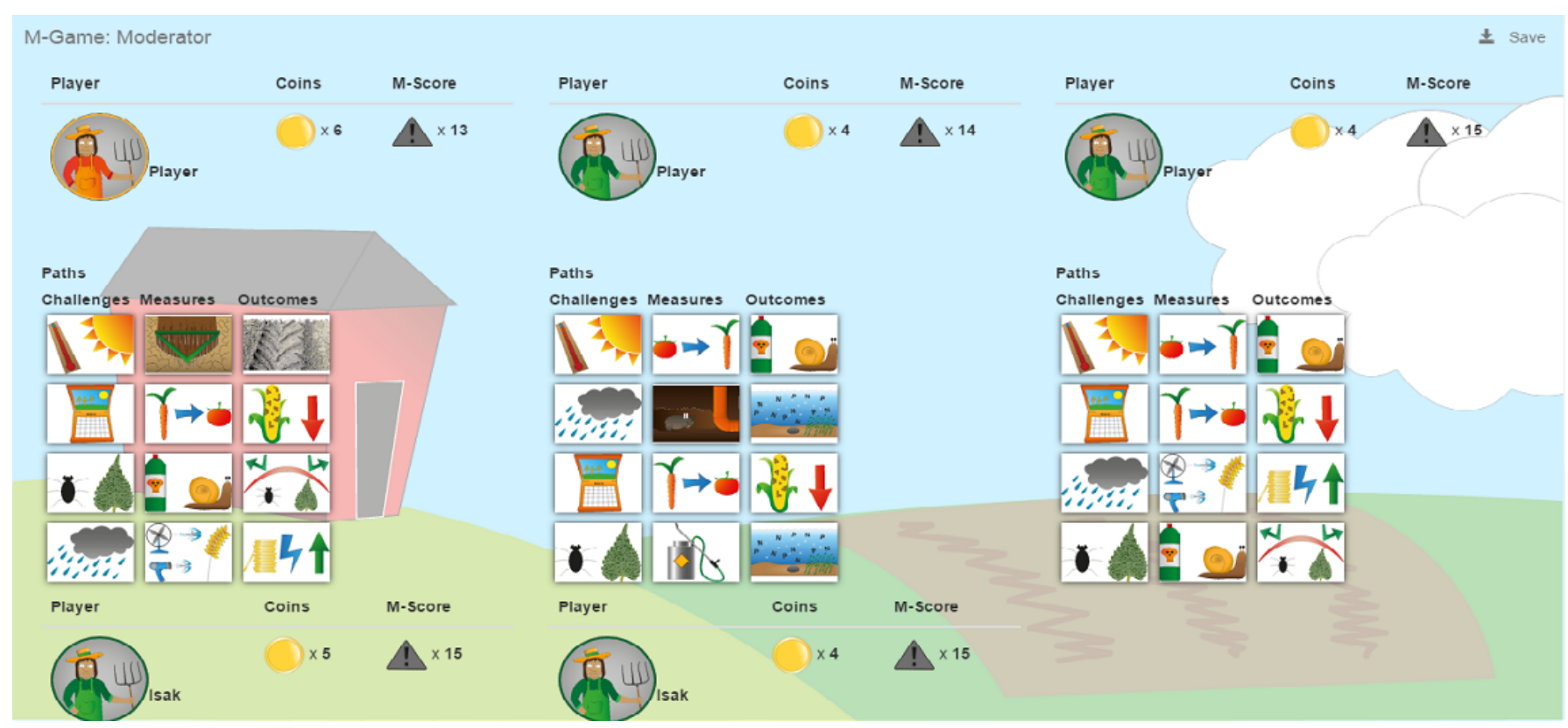

Figure 1. The Maladaptation Game for Nordic Agriculture. Screenshot from player session that shows a summary of players' choices of adaptation measures for each of the climate challenges, as well as the accepted potential maladaptive outcome.

perceive the credibility of game-mediated research on climate change maladaptation.

\section{Focus group methodology}

To harness new empirical findings on players' perceptions of the credibility of game-mediated research on climate change maladaptation. I used focus group (FG) literature for the study design, recruitment, moderation, and analysis of player sessions [Barbour and Kitzinger, 1999; Morgan and Krueger, 1997]. FGs are a qualitative research method and as such generate a rich understanding of participant experience and beliefs [Kitzinger, 2005; Morgan and Krueger, 1997]. Unlike other qualitative methods, such as individual interviews or participant observation, focus groups are organized group discussions. Due to the group dynamics - the opportunity for participants to share, compare, and explore ideas - FGs have been recognized as useful in exploring how knowledge and ideas develop and operate [Kitzinger, 1994; Wibeck, Abrandt Dahlgren and Öberg, 2007]. The methodology can therefore be seen as particularly relevant to the research questions and the aim of this article - the exploration of perspectives on credibility. While the focus group methodology offers insights into how participants generate, argue, counter-argue and circulate various ideas and understandings, it does not - due to the limited sample - provide statistical generalizations to a larger population. As the approach to this qualitative analysis of game-mediated research is exploratory, the recruitment process aimed for a diversity of perspectives which can inform the aim and research questions. Moreover, based on the importance of experience for environmental and climate perceptions [Akerlof et al., 2013; Myers et al., 2012], and the relevance of age and gender in terms of attitudes towards climate change [Eurobarometer, 2017], the FGs encompassed a mixture of national stakeholders from agricultural departments, 
boards, and specialized agricultural organizations, and from regional groups of farmers and extension officers (see Table 1). The groups were homogenous in terms of production as all participants had knowledge about various crop production systems, and were heterogeneous in terms of gender and age.

Table 1. Group compositions for game sessions.

\begin{tabular}{|ccccc|}
\hline Group & Gender & Age & No. of players & Experience \\
\hline 1 & Mix & $30-70$ & 5 & Farmers \\
2 & Mix & $30-70$ & 3 & Extension officers \\
3 & Mix & $30-70$ & 5 & Agricultural boards \\
4 & Mix & $30-70$ & 5 & Agricultural NGOs \\
\hline
\end{tabular}

\section{Moderating and analysing gaming sessions}

The gaming sessions lasted between 94 and 117 minutes, and started with an introduction followed by 15-20 minutes of individual playing in order for participants to individually associate with, reflect upon, and experience the game. After the individual session, I moderated a semi-structured discussion on players' choices of adaptation options and their outcomes while giving participants the opportunity to share and compare their reasoning. The discussions were structured in order to systematically address each of the challenges posed by climate change, the adaptation choices and potential maladaptive outcomes while being less structured in terms of participants' turn-taking and engagement in the discussions. If the participants raised concerns about the content of the game, e.g. ideas, representations, or storytelling, I posed follow-up questions in order to understand their views. The discussions were recorded and transcribed verbatim, and the analysis procedure followed manual coding and was structured according to the theoretical framework, including participating players' interactions and joint construction of game-mediated research on climate change maladaptation [cf. Marková et al., 2007]. I treated the focus group transcriptions as one text, examining recurring responses to the game narrative. Furthermore, the participants were informed, both in writing and orally, about the research project, the aim of the focus group session, the recording, the analysis procedure and their anonymity. All participants gave their consent to be recorded and for the results to be used for research purposes.

Results

This section comprises three sub-sections reflecting the theoretical framework and the main findings; namely, that players understand the communication of climate (mal)adaptation through perceived consistency in message character, judgement of game-mediated suggestions, and the perceived credibility of information sources (frame articulators). Each of these is discussed as follows.

Frame consistency - the correspondence between game-articulated claims and suggested actions

Frame consistency in the context of The Maladaptation Game refers to the perceived congruence between game-articulated claims on climate change, adaptation and 
maladaptation. This congruence may turn into inconsistency if beliefs or claims are seen as contradictory or if claims and actions are contradictory [Benford and Snow, 2000]. In theory, consistency is hypothesized to be a resource influencing the overall judgement of information credibility and thus partly explains why some information seems to be effective or to resonate with the intended audience while other information does not.

At the beginning of each game session, the moderator explained the game's logic: how challenges are related to adaptation measures and their potentially negative effects.

The storyline, in its entirety, is based on analytical and conceptual models of climate change adaptation and maladaptation [cf. IPCC, 2014; Juhola, Glaas et al., 2016] and presents a causal succession of climate change challenges, adaptation options, and potential effects. In relation to the perceived correspondence between challenges, adaptation and potential maladaptive outcomes, the players discussed consistency in two different ways: perceived lack of adaptation actions or the ability to combine several actions as illustrated by the following excerpt:

\begin{abstract}
M3 But in theory - if you take the four options, it [practising crop rotation] is probably the best. But then, reality will not really be so, but will require both chemical and mechanical control, possibly even with plant rotation, but in theory it was an easy choice for our game here and now.

\section{/.../ 7 lines omitted}

M1 I also thought that among the alternatives that existed, I thought the answer was fairly given. But you must have a combination as well. There is a big difference between where we are in the country, which crop rotations you must have and think about, and depending on which crops you grow and how often they can recur in the crop rotation, and there is a very big difference in different places in the country. (FG 3)
\end{abstract}

On the challenge of Increased risk of pests and weeds, participant M3 argued that "in theory", that is, within the game play, he favours one of the presented adaptation measures. However, the player makes a distinction between the game play and "real life" in which, he argues, a combination of adaptation options would be required. Several players agree with the stated the need for a combination of adaptation options, finally emphasized by player M1 who argues that a combination of measures is necessary due to geographical variations, and differing crop requirements on adaptation options. The same type of statement - the need for a combination of measures - was raised in other groups: "more measures would be used" (FG 2), "Can you only choose one adaptation measure?" (FG 1).

In addition to a desire to combine several actions, the players also wanted to add an in-game design feature to address the suggested maladaptive outcome:

K4 It was hard to just pick one thing, because one would like to do several things. One might lead to the other if you choose... /. . / There was increased drainage, increased nutritional leakage, then I wanted structural liming afterwards, for example, because then you counteract it.

/.../

K1 Like continue in the lead. (FG 2) 
Participants started to discuss the game options for adapting to increased precipitation; $\mathrm{K} 4$ raised the matter of responding to the suggested maladaptive outcome. By referring to the causal structure of the game play, in which "one might lead to the other", K4 exemplifies the statement by giving an example of the desire to apply structural liming while the game design did not allow for that particular option. K1 continued to reaffirm the argument, and the discussion ended with a shared perception that the game design lacked choices reflecting the participants' perceptions of logical sequence. The quotation shows a recurring argumentation in all groups showing the respondents' feelings of not "coming to an end". Based on their way of reasoning, participants claimed they would handle the negative effect generated by previous game choices. Another respondent says that: "More options are needed, you need to have something to choose, what do you do to the negative effect? I accept it because I know it is going in many other ways, but it does not appear here." (FG 4).

In parallel to the perceived lack of adaptation actions other than those generated in the game, participants provided additional examples of adaptation measures. For instance, in response to increased participation, players in group three suggested "cutting the edges instead of digging open ditches", "getting the basics right - a good crop on well-drained ground", or wetland constructions to meet the extremes of simultaneously wetter and drier climates. Further examples generated by the focus group respondents of additional adaptation measures included plant protection, plant breeding and GMO in response to an increased risk of pest outbreaks. Furthermore, respondents also discussed alternative measures to adapt to droughts. While the game suggests that drought may be addressed via the measures "Install irrigation infrastructure", "Change crops", "Plough sub-soil" or "Take out crop insurance", respondents lacked alternative adaptation options:

K3 I thought of such a crop as potatoes, it must apply to other crops too. There are, for example, varieties that are more resistant to drought than others /.../ but that wasn't an alternative here.

M2 It was to grow other crops.

K3 Yes, it was to grow other crops, but it can be enough just to change variety and choose to change to a variety that works better. (FG 4)

Participant K3 suggests the possibility of adapting to drought by changing the crop variety to one that is more drought-resistant, but simultaneously points out that such an adaptation action was not offered by the game. The player, M2, continues by saying that one option in the game was to grow other crops. K3 again reinforces her argument that "it can be enough just to change variety". The above illustrations shows participants' reasoning about congruence and empirical credibility - between game-articulated adaptation measures and self-generated options in response to climate challenges - and indicates a discrepancy between game-mediated information and adaptation actions suggested by the players. The analysis of consistency - a perceived lack of adaptation actions and the ability to combine several actions - concludes that participants perceive the game as presenting a simplified picture of agricultural practices. In addition to this perceived shortage in the number of adaptation options and the possibility to combine them, participants contended that the game worked well, as illustrated by the many discussions on the pros and cons of various climate adaptation actions in response to several dimensions of climate change. 

world

Empirical credibility involves the game players' ability to verify the claims underpinning the game content on climate maladaptation. Benford and Snow [2000] refer to empirical credibility as the perceived "fit" — from the player's point of view - between information presented in the game and the players' experiences.

As an introduction to the gaming sessions on climate change adaptation and maladaptation, the moderator asked about participants' experiences of agriculture's vulnerability to climate change. Many of the focus group participants expressed their concern about the summer's heatwave combined with previous experiences of heavy precipitation. As these initial discussions - expressed before the game play was introduced - reflect the same challenges as presented in the game, the game can be seen to support the "fit" between the challenges presented in the game and the challenges participants experience in their practice. The transcriptions contain examples of both adaptation measures and maladaptive outcomes that resonate with the players' experiences. This is an example of players agreeing with some of the game's proposed maladaptive outcomes:

K3 It may be true, I mean, should you have two crops you need to fertilize twice then, but I mean at the same time you have crops that grow and pick it up, so I do not see why it would really be a problem.

M2 In an ideal world there could be a nutrient uptake crop in-between if I get some generous rules. But having winter crops, growing more winter crops and preferably winter rape, would be good.

M3 I agree with what K3 said about sugar beet. We sow them at the end of March and on average we harvest them up at the end of October until mid-November, so they have a very long growing period and utilize the nitrogen very well, nitrogen and nutrients, perhaps $100 \mathrm{~kg}$ per hectare.

K3 It's the same with potatoes. We have those low nitrogen varieties and therefore I do not see this issue of drainage as being a problem, with the plant nutrients in the drainage, because I mean if I achieve a plant nutrient balance with potato crops, it shows a minus for nitrogen, it basically takes up more nitrogen than you put on. (FG 4)

Participants started to discuss increased nutrient leakage because of adaptation responses to longer growing seasons. According to The Maladaptation Game, adaptation options in response to longer growing season include 1) Change share of cropland to maize, 2) Grow more winter crops, 3) Grow new crop varieties (e.g. feed and silage maize), and 4) Increase production on marginal land. Together, the adaptation options may result in one or more of the following maladaptive outcomes: "Increased need for fertilizer input", "Decreased humus content/increased GHG emissions", "Increased risk of pests and weeds to overwinter", "Increased need for pesticides", and "Increased risk of nutrient leakage". In the above example, K3 in particular confirms the maladaptive outcome Increased nutrient leakage suggested by the game. By referring to the correlation between more crops and more fertilizer use while also introducing the possibility of nutrient uptake, K3 indicates a "fit" between maladaptive outcomes as suggested by the game and her reasoning in connection with these. Another 
participant, M2, continues to reinforce the idea of plants for nutrient uptake and also communicates his preference for the adaptation option of more winter crops. A new participant, M3, enters the discussion, giving yet another example to support the claim for plant uptake of nutrients. K3 reaffirms the argument, while providing yet another example reinforcing the idea of nutrient uptake, and the discussion ends with the shared perception that nutrient leakage is not a problem. The excerpt illustrates how game-mediated ideas on climate adaptation and potential maladaptive outcomes are circulated, adopted and co-evolved to shape the credibility of game-mediated messages on climate (mal)adaptation. Hence, the excerpt shows how participants shape their opinions in interaction with each other. The example illustrates a recurrent trend in the material, in which the players discuss the measures suggested in the game, and why they believe that one is better than another - and whether or not players consider the outcome to be maladaptive. Overall, when players verified the information underpinning the game in this way, discussions were characterized by reflections and joint explorations of game-mediated information about climate adaptation and maladaptation. However, in contrast to this perceived "fit" between game-mediated information and events in the world, participants also questioned the game content by drawing on their experiences. While the above example shows the "fit" between game-mediated information and participants" experiences and beliefs, participants also claimed that the game content was incorrect, hence the question of "misfit". This excerpt provides an example:

K4 I also choose that. And I thought, like you, that it's not groundwater but rather we use high flows and have some dams.

K2 Generally, it feels like when we think about irrigation, then we think surface water and ponds, not groundwater. (FG 2)

Participants discuss adaption options in response to temperature increases and drought. While the game suggests that one adaptation option can be to install irrigation infrastructure, with potential negative effects in terms of groundwater level, participant $\mathrm{K} 4$ rejects the use of groundwater as a source of irrigation altogether. The participant starts by affirming previously voiced arguments and makes a distinction between groundwater use and dams for irrigation. Hence, building on another player's argument, the participant voices her concern about the "misfit" between information presented in the game and her ideas on appropriate irrigation systems. K2 enters the discussion, concluding that "when we think about irrigation, we think surface water and ponds, not groundwater". Similar arguments were made in other groups: "I will of course reject it [increased water flow following increased drainage], but I do not think the claim is right" (FG 4). Similarly, in discussions on responses to precipitation, one player replies that he thinks direct sowing decreases energy use while the game suggests that direct sowing may result in increased energy costs and potential carbon dioxide emissions. The analysis indicates a recurrence across focus groups' adaptation actions and maladaptive outcomes, in that some participants experienced differences between game content and their own experience.

In summary, the first example shows a perceived "fit" between game content and the participants' reality while the second set of examples shows the participants' experiences of a "misfit" between information in the game and their own 
experience. Overall, the analysis suggests that the question of "empirical credibility" concerns the verification of information underpinning the game from an audience viewpoint. While this analysis does not intend to determine which argument is "right" or "wrong", instead analysing how a specific audience attributes credibility, it concludes that players attribute empirical credibility to The Maladaptation Game by judging the resonance between game content and their own experiences and beliefs.

\section{Credibility of the frame articulators - the hidden information sources}

While the moderator informed players in the introduction to the gaming sessions that The Maladaptation Game was based on research findings, the game itself contains no explicit references to the research data underpinning the game. The following excerpt illustrates players' questioning of what is articulated in the game:

K3 No, saying this is like swearing in church, but I choose to be able to use pesticides, and I do not think, I do not understand that it automatically gives a worse product. /.../Why is that so, you mean? Who says it does? (FG 1)

The discussion concerned what "product quality" means, and while the game suggests that the application of more chemicals for pest control results in a decrease in product quality, player K3 strongly opposes that suggestion. After contradicting the information, $\mathrm{K} 3$ asks the research team - the moderator and one project researcher - why pesticides would decrease product quality. Immediately after asking the project team, she rephrases he question by asking "Who says?", hence indicating the player's perception of the game's information sources as being undecipherable. While some participants and groups found the information sources for the game content to be indiscernible, other participants and groups did not explicitly discuss information sources. However, throughout the focus group discussions, participants ascribed credibility to one another:

K2 Now I have to turn to you, the plant cultivation advisor here: Do I have an increased need for pesticides because I grow an autumn crop?

K4 Yes, to some extent, and there will be many more autumn-growing weeds due to crop rotation then.

K2 Yes, so a higher weed control requirement there?

K4 Yes, I would say that. (FG 2)

The example illustrates a recurring phenomenon in the groups whereby players attribute credibility to each other. In the quotation, K2 asks another participant whether the potential maladaptive outcome of an increased need for pesticides following a change in management practices to grow more winter crops is correct. The addressed player - K4 - answers that autumn crops may require increased pesticide use, thus supporting the information provided by the game. K2 confirms K4's response but rephrases her question and asks it once again, with player K4 again reaffirming her previous statement. Thus, the excerpt illustrates that the newly appointed "expert" player provides a basis on which the participants draw conclusions about whether the information in the game matches their reality. 
Furthermore, the example also indicates an underlying desire to assess the accuracy of the information. In line with theoretical considerations, the credibility of the frame articulator is instrumental in establishing frame resonance among target audiences [Benford and Snow, 2000]; this study shows how participants assign an expert role to other participants whom they judge to be particularly knowledgeable.

In summary, the analysis of participants' assessments of the information sources suggests that information sources in game mediation of research findings may be seen as hidden and lacking in transparency. At times, participants voiced their concern that they did not know who said what and on what grounds. As notions of frame articulator credibility appear as one of three variables in the framing literature's discussions of resonance - whether or not messages are effective for influencing audiences - the implicit use of information sources may hinder players' attribution of credibility to the information given to them. Consequently, the analysis also points towards the importance of spaces for dialogues between researchers and players in order to support comprehension and meaning-making processes.

Discussion and conclusions

\section{The role of games in science and environmental communication}

By analysing players' discussions while playing The Maladaptation Game, this study has explored credibility aspects of game-mediated research on climate change maladaptation. As previous research has concluded, no matter how environmental and climate changes are framed, e.g. as a matter of social progress, economic development, or morality [Nisbet and Scheufele, 2009], people will apply implicit criteria when judging the adequacy of particular frames [Rein and Schön, 1991]. Benford and Snow [2000] suggest that such judgements arise from three factors: frame consistency, empirical credibility, and the credibility of the frame articulators/sources. Hypothetically, they argue, if a frame is consistent and if the associated claims and their articulators are deemed to be credible, the frame is likely to have a strong appeal; hence, the communication effort can be seen as effective. While players of The Maladaptation Game made some references to the congruence between articulated beliefs, claims, and actions, as well as references to the credibility of information sources, discussions recurrently circulated around the apparent "fit" between, on the one hand, the game-mediated adaptation measures and maladaptive outcomes and, on the other hand, players' practical experiences.

\section{Conceptual thinking in game design and everyday experiences among players}

While The Maladaptation Game can be seen as an example of audience-targeted climate change communication - where the abstract is made concrete and the global is made local [cf. Moser, 2010] — the literature on credibility in climate change communication suggests paying greater attention to sources, content, and processes in order to achieve successful climate change communication. [For an overview, see Asplund, 2018]. This study strengthens findings suggesting that credibility is linked to perceived scientific certainties and differing requirements for evidence [White et al., 2015; Ingram, Mills et al., 2016] by concluding that players' interpretive frameworks, and in particular their experiences, inform their perceptions of the credibility of the game's content. The many examples of 
participants' elaborations on the recontextualization of research findings to their own context and everyday practice suggest a struggle between general analytical findings and concrete applications - a general dilemma recognized in several studies [e.g. Akerlof et al., 2013; Capstick and Pidgeon, 2014; Myers et al., 2012; Weber, 2010]. These studies conclude that, while scientists learn via abstract and analytical reasoning, various audiences typically draw on associative thinking and personal experience. Hence, the different ways of making sense of climate (mal)adaptation - the analytical vs the experience-based - can be seen to be supported by different epistemologies [cf. Asplund, 2016]. In particular, this study emphasizes that the conceptual thinking behind the game content clashes with players' everyday experiences and practice, resulting in the game losing credibility with some players. One possible way to avoid this loss of credibility in the case of The Maladaptation Game could be to introduce the player's context, such as specific geographic settings or farm types, to a greater extent. More recently, studies on digital tools and interactive technologies for farming systems - albeit not for gaming — highlight issues of trust, transparency and dialogue [Jakku et al., 2019; Lazzaro et al., 2018]. Based on a study of the interplay between mistrust and insufficient information in the maize credit system, Agyekumhene et al. [2018] hold that effective intermediation arrangements are not quick fixes but processes of trial and error, and learning by doing. As Ingram and Gaskell [2018, p. 1] put it: "A key challenge in agriculture and forestry, as in other disciplines, is taking a large body of research-based knowledge and making it meaningful to the user audience." They also conclude that meaning is provided in the continuous and iterative participation of the stakeholder community, involving domain experts, advisers and practitioners. Along this line, studies have particularly emphasized scepticism towards digital tools due to a lack of transparency [Jakku et al., 2019] and the perceived lack of usable and accessible farm-level information [Knierim et al., 2018] as important aspects of these trust-building processes.

While this study acknowledges, in line with Fitts Willoughby and Smith [2016], that games allow practitioners to tailor messages to varying audiences around the globe in a context-specific way, it also pinpoints that the challenge lies in bridging the gap between analytical and experience-based thinking. In a similar manner, Curtis [2014] notes that the main challenge for the successful integration of science into a suitable gaming environment is achieving a balance between making the game entertaining and incorporating an appropriate level of scientific accuracy. To that end, research questions that still need to be explored include: how can games based on research help to overcome these clashes between analytical and experience-based learning beyond simplifying complex data? To what extent could, and should, climate change be gamified differently depending on the audience? To increase the experience of agricultural day-to-day relevance, the point of departure for The Maladaptation Game could, for instance, more clearly start from participant narratives on daily farm management, with more analytical and aggregated research on climate change adaptation options and potential maladaptive outcomes as incentives for discussing its relevance for changed farm management.

\section{Interactions between players, moderators, and research}

Even though this study employs a limited number of participants, it strengthens findings suggesting that games cannot sufficiently provide a means of 
communication between the scientific world and society [Burnet, 2010; Curtis, 2014; Mayhew and Hall, 2012]. For instance, based on an analysis of a "science café" model focusing on overcoming the "information deficit" model, Mayhew and Hall [2012] found that effective science communication requires engagement at a personal level that meets the audience where it is in terms of both prior knowledge and social context, while making connections with the audience's daily lives. Moreover, Burnet [2010] argues that a fundamental role is played not only by the mediator, but also by the scientist. Burnet claims that the presence of an academic researcher is crucial if the aim is to create contact between the scientific world and civil society. Similarly, the present analysis of The Maladaptation Game and players' sense-making of scientific research mediated by the game suggests the relevance of a moderator skilled in bridging the gap between the conceptual level and the everyday realities of players. Furthermore, The Maladaptation Game worked well as an incentive for discussion as players shared their experiences and their reasoning on climate change adaptation and the potential maladaptive effects. In line with this, Curtis [2014] found that science-based games may serve as a stimulus for increased dialogue or contact with the scientific community because games can enable players to discuss any issues that the game raises.

In summary, in order for games to be innovative and effective tools, as suggested by the gaming literature [Dudo et al., 2014; Fitts Willoughby and Smith, 2016; Meya and Eisenack, 2018; Ouariachi, Olvera-Lobo and Gutiérrez-Pérez, 2017], this study encourages a narrative turn in line with previous calls for the rethinking of climate change communication [e.g. Doyle, 2012; Doyle, 2015]. Such a narrative turn includes a shift from science-oriented to audience-oriented game design in which the narratives of players' everyday lives are taken into consideration. Such a turn needs to take into account insights into audience perceptions of both environmental and climate change, and the communication of climate change. Bregt, A. (2018). 'The role of ICTs in improving smallholder maize farming livelihoods: the mediation of trust in value chain financing'. In: Proceedings of the European IFSA Symposia 2018.

Akerlof, K., Maibach, E. W., Fitzgerald, D., Cedeno, A. Y. and Neuman, A. (2013). 'Do people "personally experience" global warming, and if so how, and does it matter?' Global Environmental Change 23 (1), pp. 81-91. https://doi.org/10.1016/j.gloenvcha.2012.07.006.

Amars, L., Fridahl, M., Hagemann, M., Röser, F. and Linnér, B.-O. (2017). ‘The transformational potential of Nationally Appropriate Mitigation Actions in Tanzania: assessing the concept's cultural legitimacy among stakeholders in the solar energy sector'. Local Environment 22 (1), pp. 86-105. https://doi.org/10.1080/13549839.2016.1161607.

Asplund, T. (2016). ‘Natural versus anthropogenic climate change: Swedish farmers' joint construction of climate perceptions'. Public Understanding of Science 25 (5), pp. 560-575. https: //doi .org/10 .1177/0963662514559655.

- (2018). 'Communicating climate science: a matter of credibility - Swedish farmers' perceptions of climate-change information'. The International Journal of Climate Change: Impacts and Responses 10 (1), pp. 23-38. https://doi.org/10.18848/1835-7156/cgp/v10i01/23-38. 
Asplund, T., Neset, T.-S., Käyhkö, J., Wiréhn, L. and Juhola, S. (2019). 'Benefits and challenges of serious gaming - the case of "The Maladaptation Game". Open Agriculture 4 (1), pp. 107-117. https: //doi .org/10.1515/opag-2019-0010.

Attari, S. Z., Krantz, D. H. and Weber, E. U. (2016). 'Statements about climate researchers' carbon footprints affect their credibility and the impact of their advice'. Climatic Change 138 (1-2), pp. 325-338.

https://doi.org/10.1007/s10584-016-1713-2.

Barbour, R. and Kitzinger, J., eds. (1999). Developing focus group research: politics, theory and practice. London, U.K.: Sage.

Barnett, J. and O'Neill, S. (2010). 'Maladaptation'. Global Environmental Change 20 (2), pp. 211-213. https://doi.org/10.1016/j.gloenvcha.2009.11.004.

Benford, R. D. and Snow, D. A. (2000). 'Framing processes and social movements: an overview and assessment'. Annual Review of Sociology 26 (1), pp. 611-639. https://doi.org/10.1146/annurev.soc.26.1.611.

Burnet, F. (2010). 'More scientists and less surrogates'. JCOM 09 (02), C04. https://doi.org/10.22323/2.09020304.

Capstick, S. B. and Pidgeon, N. F. (2014). 'Public perception of cold weather events as evidence for and against climate change'. Climatic Change 122 (4), pp. 695-708. https://doi.org/10.1007/s10584-013-1003-1.

Curtis, V. (2014). 'Public engagement through the development of science-based computer games: the Wellcome Trust's "Gamify your PhD" initiative'. Science Communication 36 (3), pp. 379-387. https://doi.org/10.1177/1075547013492436.

Dewulf, A., Gray, B., Lewicki, R., Putnam, L., Aarts, N., Bouwen, R. and van Woerkum, C. (2009). 'Disentangling approaches to framing in conflict and negotiation research: a meta-paradigmatic perspective?' Human Relations 62 (2), pp. 155-193.

Doyle, J. (2012). ‘Here today: thoughts on communicating climate change'. In: Residence project with artist David Harradine.

- (4th June 2015). 'Making climate change meaningful: celebrity vegans and the cultural politics of meat and dairy consumption'. Harvard College Review of Environment and Society.

Dudo, A., Cicchirillo, V., Atkinson, L. and Marx, S. (2014). ‘Portrayals of technoscience in video games: a potential avenue for informal science learning'. Science Communication 36 (2), pp. 219-247. https://doi.org/10.1177/1075547013520240.

Egeru, A. (2016). 'Climate risk management information, sources and responses in a pastoral region in East Africa'. Climate Risk Management 11, pp. 1-14. https://doi.org/10.1016/j.crm.2015.12.001.

Eurobarometer (2017). Special Eurobarometer 468: Attitudes of European citizens towards the environment.

Fiske, J. (1990). Introduction to communication studies. London, U.K.: Routledge.

Fitts Willoughby, J. and Smith, H. (2016). 'Communication strategies and new media platforms: exploring the synergistic potential of health and environmental communication'. Science Communication 38 (4), pp. 535-545. https://doi.org/10.1177/1075547016648151. 
Hahn, U., Harris, A. J. L. and Corner, A. (2016). 'Public reception of climate science: coherence, reliability, and independence'. Topics in Cognitive Science 8 (1), pp. 180-195. https://doi.org/10.1111/tops. 12173.

Hansen, J., Marx, S. and Weber, E. (2004). The role of climate perceptions, expectations, and forecasts in farmer decision making: the Argentine Pampas and South Florida. Technical report 04-01. Palisades, NY, U.S.A. https://doi.org/10.7916/D8N01DC6.

Ingram, J. and Gaskell, P. (2018). 'Reflections on co-constructing a digital adviser with stakeholders in agriculture and forestry'. In: Proceedings of the European IFSA Symposia 2018.

Ingram, J., Mills, J., Dibari, C., Ferrise, R., Ghaley, B. B., Grønbech Hansen, J., Iglesias, A., Karaczun, Z., McVittie, A., Merante, P., Molnar, A. and Sánchez, B. (2016). 'Communicating soil carbon science to farmers: incorporating credibility, salience and legitimacy'. Journal of Rural Studies 48, pp. 115-128. https://doi.org/10.1016/j.jrurstud.2016.10.005.

IPCC (2007). Contribution of working group II to the fourth assessment report of the Intergovernmental Panel on Climate Change. Ed. by M. L. Parry, O. F. Canziani, J. P. Palutikof, P. J. van der Linden and C. E. Hanson. Cambridge, U.K. and New York, NY, U.S.A.: Cambridge University Press.

- (2014). Climate change 2014: impacts, adaptation, and vulnerability. Part A: global and sectoral aspects. Contribution of working group II to the fifth assessment report of the Intergovernmental Panel on Climate Change. Ed. by C. B. Field, V. R. Barros, D. J. Dokken, K. J. Mach, M. D. Mastrandrea, T. E. Bilir, M. Chatterjee, K. L. Ebi, Y. O. Estrada, R. C. Genova, B. Girma, E. S. Kissel, A. N. Levy, S. MacCracken, P. R. Mastrandrea and L. L. White. Cambridge, U.K. and New York, NY, U.S.A.: Cambridge University Press.

Jakku, E., Taylor, B., Fleming, A., Mason, C., Fielke, S., Sounness, C. and Thorburn, P. (2019). "'If they don't tell us what they do with it, why would we trust them?" Trust, transparency and benefit-sharing in Smart Farming'. NJAS — Wageningen Journal of Life Sciences 90-91, p. 100285. https://doi.org/10.1016/j.njas.2018.11.002.

Jarreau, P. B., Altinay, Z. and Reynolds, A. (2017). 'Best practices in environmental communication: a case study of Louisiana's coastal crisis'. Environmental Communication 11 (2), pp. 143-165. https://doi.org/10.1080/17524032.2015.1094103.

Juhola, S., Glaas, E., Linnér, B.-O. and Neset, T.-S. (2016). 'Redefining maladaptation'. Environmental Science E Policy 55, pp. 135-140. https://doi.org/10.1016/j.envsci.2015.09.014.

Juhola, S., Klein, N., Käyhkö, J. and Neset, T.-S. S. (2017). ‘Climate change transformations in Nordic agriculture?' Journal of Rural Studies 51, pp. 28-36. https://doi.org/10.1016/j.jrurstud.2017.01.013.

Kitzinger, J. (2005). 'Focus group research: using group dynamics to explore perceptions, experiences and understandings'. In: Qualitative research in health care. Ed. by I. Holloway. Maidenhead, U.K.: Open University Press, pp. 56-70.

Kitzinger, J. (1994). 'The methodology of focus groups: the importance of interaction between research participants'. Sociology of Health and Illness 16 (1), pp. 103-121. https://doi.org/10.1111/1467-9566.ep11347023. 
Knierim, A., Borges, F., Lee Kernecker, M., Kraus, T. and Wurbs, A. (2018). 'What drives adoption of smart farming technologies? Evidence from a cross-country study'. In: Proceedings of the European IFSA Symposia 2018.

Kotcher, J. E., Myers, T. A., Vraga, E. K., Stenhouse, N. and Maibach, E. W. (2017). 'Does engagement in advocacy hurt the credibility of scientists? Results from a randomized national survey experiment'. Environmental Communication 11 (3), pp. 415-429. https://doi.org/10.1080/17524032.2016.1275736.

Lazzaro, M., Paree, P., Guidotti, D., Koltsida, P., Benians, S., Barberi, P. and Toli, E. (2018). 'Digital tools co-creation to ease the dialog among farmers' communities with diverse visions. A practical case with conventional and organic farmers in CAPSELLA'. In: Proceedings of the European IFSA Symposia 2018.

Li, N., Hilgard, J., Scheufele, D. A., Winneg, K. M. and Hall Jamieson, K. (2016). 'Cross-pressuring conservative Catholics? Effects of Pope Francis' encyclical on the U.S. public opinion on climate change'. Climatic Change 139 (3-4), pp. 367-380. https://doi .org/10.1007/s10584-016-1821-z.

Marková, I., Linell, P., Grossen, M. and Salazar Orvig, A. (2007). Dialogue in focus groups: exploring socially shared knowledge. London, U.K.: Equinox.

Mayhew, M. A. and Hall, M. K. (2012). 'Science communication in a Café Scientifique for high school teens'. Science Communication 34 (4), pp. 546-554. https://doi.org/10.1177/1075547012444790.

McDonald, E. (20th April 2017). ‘The global games market will reach $\$ 108.9$ billion in 2017'. Newzoo.

URL: https://newzoo.com/insights/articles/the-global-games-market-wi ll-reach-108-9-billion-in-2017-with-mobile-taking-42/.

Meya, J. N. and Eisenack, K. (2018). 'Effectiveness of gaming for communicating and teaching climate change'. Climatic Change 149 (3-4), pp. 319-333. https://doi.org/10.1007/s10584-018-2254-7.

Morgan, D. L. and Krueger, R. A. (1997). The focus group kit. Volumes 1-6. Thousands Oaks, CA, U.S.A. and London, U.K.: Sage Publications.

Moser, S. C. (2010). 'Communicating climate change: history, challenges, process and future directions'. Wiley Interdisciplinary Reviews: Climate Change 1 (1), pp. 31-53. https://doi.org/10.1002/wcc.11.

Myers, T. A., Maibach, E. W., Roser-Renouf, C., Akerlof, K. and Leiserowitz, A. A. (2012). 'The relationship between personal experience and belief in the reality of global warming'. Nature Climate Change 3 (4), pp. 343-347. https://doi.org/10.1038/nclimate1754.

Neset, T.-S., Wiréhn, L., Klein, N., Käyhkö, J. and Juhola, S. (2019). ‘Maladaptation in Nordic agriculture'. Climate Risk Management 23, pp. 78-87. https://doi.org/10.1016/j.crm.2018.12.003.

Nisbet, M. C. and Scheufele, D. A. (2009). 'What's next for science communication? Promising directions and lingering distractions'. American Journal of Botany 96 (10), pp. 1767-1778. https://doi.org/10.3732/ajb.0900041.

Olesen, J. E., Børgesen, C. D., Elsgaard, L., Palosuo, T., Rötter, R. P., Skjelvåg, A. O., Peltonen-Sainio, P., Börjesson, T., Trnka, M., Ewert, F., Siebert, S., Brisson, N., Eitzinger, J., van Asselt, E. D., Oberforster, M. and van der Fels-Klerx, H. J. (2012). 'Changes in time of sowing, flowering and maturity of cereals in Europe under climate change'. Food Additives $\mathcal{E}$ Contaminants: Part A 29 (10), pp. 1527-1542. https://doi .org/10.1080/19440049.2012.712060. 
Olesen, J. E. and Bindi, M. (2002). 'Consequences of climate change for European agricultural productivity, land use and policy'. European Journal of Agronomy 16 (4), pp. 239-262. https://doi.org/10.1016/s1161-0301(02)00004-7.

Ouariachi, T., Olvera-Lobo, M. D. and Gutiérrez-Pérez, J. (2017). ‘Analyzing climate change communication through online games: development and application of validated criteria'. Science Communication 39 (1), pp. 10-44. https://doi.org/10.1177/1075547016687998.

Rein, M. and Schön, D. (1991). 'Frame-reflective policy discourse'. In: Social sciences and modern states: national experiences and theoretical crossroads. Ed. by P. Wagner, C. Hirschon Weiss, B. Wittrock and H. Wollmann. Cambridge, U.K.: Cambridge University Press, pp. 262-289. https://doi.org/10.1017/cbo9780511983993.012.

Sleeth-Keppler, D., Perkowitz, R. and Speiser, M. (2017). 'It's a Matter of Trust: American Judgments of the Credibility of Informal Communicators on Solutions to Climate Change'. Environmental Communication 11 (1), pp. 17-40. https://doi.org/10.1080/17524032.2015.1062790.

Snow, D. A. and Benford, R. D. (1988). 'Ideology, frame resonance, and participant mobilization'. International Social Movement Research 1 (1), pp. 197-218.

Twongyirwe, R., Sheil, D., Sandbrook, C. G. and Sandbrook, L. C. (2015). 'REDD at the crossroads? The opportunities and challenges of REDD for conservation and human welfare in South West Uganda'. International Journal of Environment and Sustainable Development 14 (3), pp. 273-298. https://doi.org/10.1504/ijesd.2015.070136.

Weber, E. U. (2010). 'What shapes perceptions of climate change?' Wiley Interdisciplinary Reviews: Climate Change 1 (3), pp. 332-342. https://doi.org/10.1002/wcc. 41.

White, D. D., Wutich, A. Y., Larson, K. L. and Lant, T. (2015). 'Water management decision makers' evaluations of uncertainty in a decision support system: the case of WaterSim in the decision theater'. Journal of Environmental Planning and Management 58 (4), pp. 616-630. https://doi.org/10.1080/09640568.2013.875892.

Wibeck, V. (2014). 'Enhancing learning, communication and public engagement about climate change - some lessons from recent literature'. Environmental Education Research 20 (3), pp. 387-411. https://doi.org/10.1080/13504622.2013.812720.

Wibeck, V., Abrandt Dahlgren, M. and Öberg, G. (2007). 'Learning in focus groups: an analytical dimension for enhancing focus group research'. Qualitative Research 7 (2), pp. 249-267. https://doi.org/10.1177/1468794107076023.

Wijman, T. (30th April 2018). 'Mobile revenues account for more than $50 \%$ of the global games market as it reaches $\$ 137.9$ billion in $2018^{\prime}$. Newzoo.

URL: https://newzoo.com/insights/articles/global-games-market-reache s-137-9-billion-in-2018-mobile-games-take-half/.

Wolf, J. and Moser, S. C. (2011). 'Individual understandings, perceptions, and engagement with climate change: insights from in-depth studies across the world'. Wiley Interdisciplinary Reviews: Climate Change 2 (4), pp. 547-569. https://doi.org/10.1002/wcc.120. 
Therese Asplund: Research Fellow at the Department of Thematic Studies-Environmental Change, and Centre for Climate Science and Policy Research, Linköping University, Sweden, focusing on environmental, and climate change perceptions and in particular how these are formed and withheld through dialogical processes. E-mail: therese.asplund@liu.se.

How to cite

Asplund, T. (2020). 'Credibility aspects of research-based gaming in science communication - the case of The Maladaptation Game'. JCOM 19 (01), A01. https://doi.org/10.22323/2.19010201. 